\title{
Comparative Study between Physical Properties of Virgin Oil and Re-Refining Oil
}

\author{
Bestoon M. Faqi-Ahmed, Karzan A. Omar* \\ Department of Chemistry, Faculty of Science and Health, Koya University, Koy Sanjaq, Iraq \\ Email: *karzan.abdulkareem@koyauniversity.org
}

How to cite this paper: Faqi-Ahmed, B.M. and Omar, K.A. (2017) Comparative Study between Physical Properties of Virgin Oil and Re-Refining Oil. Open Access Library Journal, 4: e3393.

https://doi.org/10.4236/oalib.1103393

Received: January 21, 2017

Accepted: February 17, 2017

Published: February 20, 2017

Copyright $\odot 2017$ by authors and Open Access Library Inc.

This work is licensed under the Creative Commons Attribution International License (CC BY 4.0).

http://creativecommons.org/licenses/by/4.0/

\section{(c) (i) Open Access}

\begin{abstract}
The lubricating oils are essential for operating engine with high efficiency. Therefore, the physical properties of oil such as flash point, pour point, kinematic viscosity, specific gravity and the American Petroleum Institute are necessary to be studied to indicate good quality of the lubricating oil. In this study, we compare the physical properties of two virgin oils with re-refining oil. The results indicated slight differences in the re-refining oil properties in comparing to virgin oils due to larger values of specific gravity and carbon residue, and lower value of flash point, pour point, kinematic viscosity, and American Petroleum Institute.
\end{abstract}

\section{Subject Areas}

Petrochemistry, Physical Chemistry

\section{Keywords}

Virgin Oil, Re-Refined Oil, Physical Properties

\section{Introduction}

Motor oil plays a significant role in conserving motor lifetime working and it does not use just as lubrication, but also carrying away heat and dissolving contamination [1]. Motor oil forms a thin layer of oil with a thickness of (1 $100-\mathrm{lm}$ ) two separate metal parts and contrasting solid bodies from each other to reduce motor form fractions and keep metal surfaces clean [2]. Motor oils consist of two important parts which are base oils derived from crude oil or neutral sources that are manufactured by chemical processes and additives which are normally added to the motor oil to improve it. The motor oils are produced by a refining process of most viscose portion of crude oil. Therefore, there are slight differences in their elemental analysis due to depending on the crude oil and 
their main physical-chemical characteristic. This is covered under the American standard for testing material (ASTM) [3]. Motor oils are formed of petroleum base which consists of essential complex mixtures of hydrocarbon molecules and mostly composed of isoalkanes having less long branches and the monoaromatics and mono cycloalkanes which have several short branches on the ring [4]. These hydrocarbon molecules usually range from low viscosity up to more viscose motor oil and their carbon atoms in the range of 20 to 34. Therefore, on the basis of their chemical composition, the motor oil molecules can be divided into four groupings [5], which are Paraffinic, Naphthenic, Member ring structures and Aromatic [6] [7]. The motor oils are useful to inhibit corrosion, cleaning, sealing improvement, which allows eliminating the heat of friction and combustion until the engine parts remain within the operating tolerances. In this operation, the lubrication system is designed to minimize resistance because of friction in moving parts. Therefore, good lubrication oil in an engine optimizes the yield by reducing the mechanical losses due to friction [8]. The motor oil can be re-refined by several methods such as Acid-Clay Treatment [9], Solvent Extraction [10], Membrane Filtration [11] etc., but the batch acid clay is a major process for re-refining motor oil in the Kurdistan Region as shown in Figure 1 [12].

In this study, we focus on the physical properties of virgin and re-refining motor oils used in the lubrication of an engine. The physical properties have been carried out by the determination of the flash point, pour point, specific gravity, API, kinematic viscosity of different types of lubrication oils.

\section{Material and Method}

All motor oils were purchased in the Kurdistan region market.

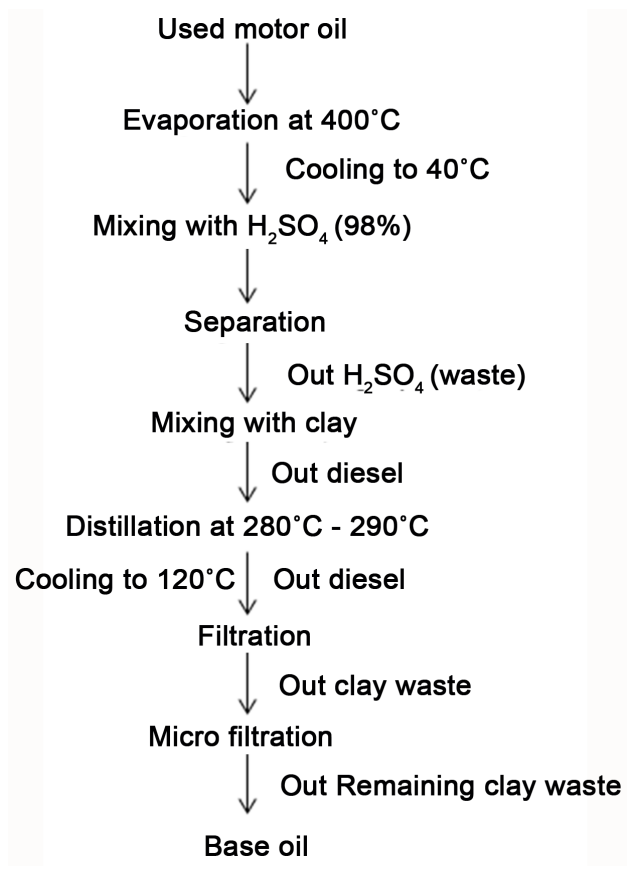

Figure 1. Diagram of re-refining motor oil. 


\subsection{Flash Point}

The test cup filled with the sample so that the top of the test specimen is exactly on the filling mark, and then placed the test cup in the center of the heater. The temperature of the test cup and the sample was not exceeded $56^{\circ} \mathrm{C}(100 \mathrm{~F})$ below the expected flash point. The temperature raised gradually until the flash point approach and the flash point recorded when a vapor above the surface of the liquid ignites.

\subsection{Pour Point}

The sample was poured into the test jar to the level mark. The sample is heated in a water bath until it sufficiently fluid to pour into the test jar. The test jar was closed with the cork carrying the high-pour thermometer, and then the sample cooled at a specified rate and examined at intervals of $3^{\circ} \mathrm{C}$ for flow characteristics.

\subsection{Kinematic Viscosity}

The time is measured in seconds for a fixed volume of liquids to flow under gravity through the capillary a calibrated Ubbelohede Viscometer under a reproducible driving head and at a closely controlled temperature $\left(40^{\circ} \mathrm{C}\right.$ and $100^{\circ} \mathrm{C}$ ). The kinematic viscosity is the product of the measured flow time and the calibration constant of the Viscometer calculated by Equation (1) [13].

$$
V=K \times T
$$

where $V=$ determined kinematic viscosity values in $\mathrm{mm}^{2} / \mathrm{s}, K=$ calibration constant of Viscometer, $\mathrm{mm}^{2} / \mathrm{s}^{2}\left(0.1\right.$ for $100^{\circ} \mathrm{C}, 1$ for $\left.40^{\circ} \mathrm{C}\right)$ and $T=$ measured flow time in seconds.

\subsection{Carbon Residue}

After the sample being weighed into a special glass bulb (glass coking bulb), is placed in a metal furnace maintained at approximately $550^{\circ} \mathrm{C}$. The sample is then quickly heated to the point at which all volatile matter is evaporated out of the bulb with or without decomposition while the heavier residue remaining in the bulb undergoes cracking and subject to further slow decomposition or slight oxidation due to the possibility of breathing air into the bulb. After a specified heating period, the bulb is removed the bath, cooled in desiccators, and again weighed. The residue remaining is calculated as a percentage of the original sample by Equation (2) [14].

$$
\% C \cdot r=\frac{m 3-m 1}{m 2-m 1} \times 100
$$

where, \%C. $r=$ carbon residue percentage, the $m 1=$ mass of the empty glass coking bulb, the $m 2$ = mass of empty glass coking bulb+ mass of $(4 \mathrm{ml})$ sample, the $m 3=$ mass of empty glass coking bulb+ mass of $(4 \mathrm{ml})$ sample after burning.

\subsection{Density and Specific Gravity}

The sample is brought to a specified temperature and a test portion is transferred to a hydrometer cylinder that has been brought to approximately the 
same temperature. The appropriated hydrometer, also at similar temperature equilibrium has been reached, the hydrometer scale is red, and the temperature of the test portion is taken. The observed hydrometer reading is reduced to the referenced temperature by means of the petroleum measurement tables. If necessary, the hydrometer cylinder and its content are placed in a constant temperature bath to avoid excessive temperature variation during the test. The sample density and specific gravity at $15.6^{\circ} \mathrm{C}$ calculated by Equations (3) and (4) [15].

$$
d=\frac{w t \text { of sample }}{v \text { of sample }}
$$

where $d=$ density of the sample, $w t=$ weight of sample and $v=$ volume of sample.

$$
S p \cdot g r=\frac{d \text { of sample }}{d \text { of distilled water }}
$$

\subsection{API Gravity}

API gravity (American Petroleum Institute) was a measured of the lightness or heaviness of petroleum, which is related to density and specific gravity by Equation (5) [15].

$$
A P I \cdot g r=\frac{141.5}{S p \cdot g r\left(\frac{60^{\circ}}{60} F\right)}-131.5
$$

\subsection{Water and Sediments}

Equal volume $(25 \mathrm{ml})$ of motor oil and water saturated toluene are placed into a cone-shaped centrifuge tube. After centrifugation, the volume of the water and sediment in the tube was read [16].

\section{Results and Discussion}

The flash point of re-refining oil is lower than both virgin oils due to possible contamination with lower boiling point materials during refining process. The pour point of re-fining oil is greater than both virgin oils, which indicated present impurities in the re-refining oil leads it to freezing point early. The larger value of specific gravity of re-refining oil observed in comparing to virgin oils due to present heavy component in the re-refining, oil and at the same time it decreases the API gravity due to the increased weight ration of carbon to hydrogen. The kinematic viscosity of re-refining oil less than virgin oils because of the re-refining process occurred at high temperature, which is leading to decrease the viscosity oil and possible contamination.

The larger quantity of carbon resides indicated in the re-refining oil due to using high temperature for re-refining oil again after the oil being used in the car and losses its lifetime. Also, the water and sediment test are very important to ensure there are no water and sediment present in the re-refining oil because if the re-refining oil contaminated by water and sediment causes problems to a burner and filter by forming emulsion which hardly can be removed as shown in Table 1. 
Table 1. Physical properties of virgin oils and re-refined oil.

\begin{tabular}{ccccc}
\hline \multirow{2}{*}{ Tests } & \multicolumn{4}{c}{ Samples } \\
\cline { 2 - 5 } & $\begin{array}{c}\text { Germany } \\
\text { Virgin oil 15 W/40 }\end{array}$ & $\begin{array}{c}\text { Russian } \\
\text { Virgin oil 15 W/40 }\end{array}$ & $\begin{array}{c}\text { Kurdistan-Region/Iraq } \\
\text { Re-refining oil } 15 \text { Value }\end{array}$ \\
\hline Flash point ${ }^{\circ} \mathrm{C}$ & 235 & 231 & 214 & $<0.001$ \\
Pour point ${ }^{\circ} \mathrm{C}$ & -25 & -22 & -10 & $<0.001$ \\
Specific gravity & 0.8611 & 0.8667 & 0.8813 & 0.997 \\
API & 32.82 & 31.76 & 29.05 & 0.291 \\
Kinematic viscosity $(\mathrm{cSt})$ & 193.5 & 189.6 & 169.7 & $<0.001$ \\
Carbon residue & 0.5231 & 0.5912 & 1.31 & 0.838 \\
Water \& sediment $(\mathrm{mL})$ & 0.0 & 0.0 & 0.0 & Nan \\
\hline
\end{tabular}

${ }^{*}$ Statistically significant $<0.05$.

\section{Conclusion}

In this comparative study, the physical properties of both virgin oils and re-refining oil have been studied. They were indicating that the physical property of re-refining oil has been slightly changed compared to the virgin oils. The flash point and pour point were lower than virgin oils and due to the presence of heavy component, the specific gravity of re-refining oil was higher than both virgin oils. Also, the high quantity of carbon residue which caused reduced in the API being observed in re-refining oil in comparing virgin oils.

\section{Acknowledgements}

The authors are grateful to Dr. Tara Fuad Tahir: head of chemistry department and chemistry staff for their cooperation and support.

\section{References}

[1] Abdel-Azim, A. and Rash, M. (2001) Polymeric Additive for Improving Flow Properities and Viscosity Index of Lubricating Oils. Journal of Polymer Research, 8, 111-118. https://doi.org/10.1007/s10965-006-0140-x

[2] Abou El Naga, H.H. and Salem, A.E. (1984) Effect of Worn Metals on the Oxidation of Lubricating Oils. California Scientific Research, 96, 267-283. https://doi.org/10.1016/0043-1648(84)90041-3

[3] Rudnick, L.R. (2006) Synthetic, Mineral Oils, and Bio Based Lubricants: Chemistry and Technology. CRC/Taylor and Francis, Boca Raton, London, New York.

[4] Cock, V.R. (1998) Laboratory Handbook for Mineral Oil and Organic Oil Analysis. 3d Edition, Pergamum Limited, London Academy Press, London, 234-239.

[5] ASTM International (2004) ASTM D 4628: Standard Test Method for Analysis of Barium, Calcium, Magnesium, and Zinc in Unused Lubricant Oils by Atomic Absorption Spectrometry. ASTM International, West Conshoken, 1.

[6] ASTM International (2004) ASTM D 4739: Standard Test Method for Base Number of Petroleum Products by Potentiometric Titration. ASTM International, West Conshoken, 1.

[7] ASTM International (2004) ASTM D 524: Standard Test Method for Rams Bottom 
Carbon Residue of Petroleum Products. ASTM International, West Conshoken, 1.

[8] Morinaa, N.A., Haquea, T. and Voonga, M. (2007) Compatibility between Tribological Surfaces and Lubricant Additives-How Friction and Wear Reduction Can Be Controlled by Surface/Lube Synergies. Tribology International, 40, 1680-1695. https://doi.org/10.1016/j.triboint.2007.01.019

[9] Fox, M.F., George E.D. and Totten, E. (2007) Sustainability and Environmental Aspects of Lubricants. In: Totten, G.E., Ed., Hand Book of Lubrication and Tribology, Chapter 13, CRC Press, Boca Raton.

[10] Rinco, N.J., Can, I.P. and Garcia, M.T. (2005) Regeneration of Used Lubricant Oil by Polar Solvent Extraction. Industrial \& Engineering Chemistry Research, 44, 4373. https://doi.org/10.1021/ie040254j

[11] Dang, G.S. (2006) Rerefining of Used Oils. A Review of Commercial Process. Journal of Wiley Inter Science, 3, 445-457.

[12] Sardasht, R.T. (1998) Re-Refining Used Motor Oil by Glacial Acetic Acid in Kurdistan Region. Master Thesis, Koya University, Koysinjaq.

[13] ASTM International (2010) ASTM D2170/D2170M-10: Standard Test Method for Kinematic Viscosity of Asphalts (Bitumens). ASTM International, West Conshohocken. https://doi.org/10.1520/D2170_D2170M-10

[14] ASTM International (2014) ASTM D189-06: Standard Test Method for Conradson Carbon Residue of Petroleum Products. ASTM International, West Conshohocken. https://doi.org/10.1520/D0189-06R14

[15] ASTM International (2011) ASTM D3142/D3142M-11: Standard Test Method for Specific Gravity, API Gravity, or Density of Cutback Asphalts by Hydrometer Method. ASTM International, West Conshohocken. https://doi.org/10.1520/D3142_D3142M-11

[16] ASTM International (2016) ASTM D1796-11: Standard Test Method for Water and Sediment in Fuel Oils by the Centrifuge Method (Laboratory Procedure). ASTM International, West Conshohocken. https://doi.org/10.1520/D1796-11R16

Submit or recommend next manuscript to OALib Journal and we will provide best service for you:

- Publication frequency: Monthly

- 9 subject areas of science, technology and medicine

- Fair and rigorous peer-review system

- Fast publication process

- Article promotion in various social networking sites (LinkedIn, Facebook, Twitter, etc.)

- Maximum dissemination of your research work

Submit Your Paper Online: Click Here to Submit

Or Contact service@oalib.com 